\title{
SISTEMA DE INFORMAÇÕES GERENCIAIS DA PRÓ-REITORIA DE EXTENSÃO
}

\author{
G. A. SILVA ${ }^{1}$, W. A. F. TABOSA ${ }^{2}$, H. M. S. FERREIRA ${ }^{3}$, V. H. A. SILVA ${ }^{4}$ \\ 1, 2, 3 e 4 Instituto Federal de Educação, Ciência e Tecnologia do Rio Grande do Norte \\ gilbert.azevedo@ifrn.edu.br - wyllys.farkatt@ifrn.edu.br - marleysheredder@gmail.com - \\ victorhugo_araujo@hotmail.com
}

Artigo submetido em outubro/2011 e aceito em dezembro/2011

\section{RESUMO}

O presente artigo apresenta um sistema de informações gerenciais desenvolvido para a Pró-reitoria de Extensão do Instituto Federal do Rio Grande do Norte. O objetivo do sistema, denominado de Sistema de Gestão de Ações da Pró-reitoria de Extensão, é registrar as atividades de extensão realizadas nos diversos campi do instituto, como programas, projetos, cursos de extensão, eventos e prestação de serviços.

No nível gerencial, o sistema pretende auxiliar a obtenção de indicadores de desempenho utilizados pela
Pró-reitoria de Extensão nas tomadas de decisão, como quantidade de docentes, técnicos e discentes envolvidos em atividades de extensão, número de ações realizadas por campus, total de cursos ofertados, eventos promovidos, dentre outros. No nível operacional, o sistema, além de facilitar o registro das atividades realizadas pela extensão institucional, deve permitir a emissão dos certificados de participação para os envolvidos nas atividades.

PALAVRAS-CHAVE: Extensão, Sistema de Gestão.

\section{MANAGEMENT INFORMATION SYSTEM FOR THE PRO-RECTOR OF EXTENSION}

\section{ABSTRACT}

This paper presents a management information system developed for the Pro-rector of Extension of the Federal Institute of Rio Grande do Norte. The purpose of this system, called Sistema de Gestão de Ações da Pró-reitoria de Extensão, is to register the extension activities, i.e. the activities related to the interaction between the Institute and the community, undertaken in the various campuses of the Institute, such as programs, projects, courses, events and services.
At the management level, the system aims to obtain performance indicators used by the Pro-rector in decision making, such as quantity of teachers, technicians and students involved in outreach activities, number of shares held by campus, number of courses offered, promoted events, among others. At the operational level, the system is aimed to facilitate the registration of the institutional extension activities and allow to issue certificates of participation for those involved in these activities.

KEY-WORDS: Extension, Management System. 


\section{SISTEMA DE INFORMAÇÕES GERENCIAIS DA PRÓ-REITORIA DE EXTENSÃO}

\section{INTRODUÇÃO}

Com a expansão da Rede Federal de Educação Profissional, Científica e Tecnológica promovida pelo governo federal, os gestores das instituições que compõem a rede passaram a manipular um volume crescente de informações relacionadas às diversas dimensões da atuação institucional. Além do aumento na quantidade dados necessários à tomada de decisões, a expansão da rede promoveu uma descentralização das informações que agora permeiam os diversos campi que compõem cada Instituto Federal.

No âmbito da Pró-reitoria de Extensão, por exemplo, é necessário catalogar as diversas atividades promovidas pela extensão institucional, como: cursos de formação inicial e continuada, eventos, projetos artísticos, culturais e esportivos, visitas técnicas, dentre outras. Para esta próreitoria, indicadores como o Grau de Envolvimento com Extensão Docente (GEED), Grau de Envolvimento com Extensão Técnico-Administrativo (GEETA) e Grau de Envolvimento com Extensão de Estudantes (GEEE) são importantes para mensurar a participação de servidores e alunos nas atividades de extensão desenvolvidas, podendo servir como parâmetros para a definição de políticas e ações institucionais para, junto com o ensino e a pesquisa, estender os benefícios da produção do conhecimento à sociedade [1].

Neste panorama, o presente artigo apresenta um sistema de informações gerenciais desenvolvido para a Pró-reitoria de Extensão. O sistema, denominado de Sistema de Gestão de Ações da Pró-reitoria de Extensão (SigaProEx), permite o registro das atividades de extensão realizadas nos diversos campi do instituto, como programas, projetos, cursos, eventos e prestação de serviços. Utilizando a Internet como meio de comunicação, o sistema possibilita que coordenadores de extensão registrem as atividades realizadas em cada campus do instituto, cadastrando os dados referentes à ação, ao pessoal envolvido na coordenação e execução das atividades e ao seu públicoalvo, como alunos e participantes de eventos.

Com as informações armazenadas em um banco de dados, o sistema facilita a realização algumas tarefas realizadas comumente pela extensão institucional. No nível operacional, por exemplo, o sistema permite a emissão dos certificados de participação para todos os envolvidos nas atividades: coordenadores de projeto, organizadores de eventos, participantes de eventos, etc. No nível gerencial, auxilia a obtenção dos indicadores de desempenho utilizados pela pró-reitoria nas tomadas de decisão, como quantidade de docentes, técnicos e discentes envolvidos em atividades de extensão, número de ações realizadas por campus, total de cursos ofertados, eventos promovidos, dentre outros.

Nas seções a seguir são apresentadas algumas informações sobre o sistema desenvolvido, ressaltando os objetivos, a modelagem do sistema e os resultados obtidos até o momento.

\section{OBJETIVO DO SISTEMA}

O Sistema de Gestão de Ações objetiva auxiliar o registro das atividades de extensão realizadas pela Pró-reitoria de Extensão do IFRN juntamente com as Coordenações de Extensão dos seus diversos campi. Para o sistema, as atividades de extensão são subdivididas em quatro grupos, com o intuito de facilitar o registro das informações: Programas, Projetos de Extensão, Cursos de Extensão e Ações de 
Extensão; esta última englobando as atividades como os eventos e prestação de serviços institucional. Desta forma, o sistema resumidamente auxilia nas seguintes tarefas:

- Cadastro de programas de extensão desenvolvidos no IFRN;

- Cadastro de projetos de extensão realizados nos diversos campi do instituto;

- Cadastro de cursos de extensão;

- Cadastro de ações de extensão: eventos e prestação de serviços, dentre outras;

- Emissão de certificados para o pessoal envolvido na coordenação e execução das atividades;

- Emissão de certificados para participantes das atividades;

- Emissão de relatórios gerenciais utilizados na obtenção de indicadores de desempenho para cada campus e para o instituto.

\section{DIMENSÕES DA EXTENSÃO E ÁREAS DO CONHECIMENTO}

Com o intuito de identificar as potencialidades do instituto e auxiliar a definição das políticas e ações relativas à extensão institucional, as atividades de extensão são classificadas quanto à dimensão e à área do conhecimento.

As dimensões da extensão foram definidas em fóruns de extensão realizados por vários institutos federais que discutiram as esferas de atuação da extensão nestas instituições [2]. No sistema desenvolvido, as dimensões da extensão identificadas no fórum foram agrupadas em dois níveis hierárquicos para facilitar o registro das atividades. A Tabela 1 mostra as dimensões utilizadas para classificação das atividades de extensão.

Tabela 1: Dimensões das Atividades de Extensão.

\begin{tabular}{|l|c|}
\hline \multicolumn{1}{|c|}{ DIMENSÃO } & SUBDIMENSÕES \\
\hline Projetos de Extensão & Projeto Cultural, Artístico e Esportivo; \\
& Projeto Social; \\
& Projeto Tecnológico \\
\hline Cursos de Extensão & Curso de Formação Inicial; \\
Curso de Formação Continuada
\end{tabular}




\begin{tabular}{|l|c|}
\hline & $\begin{array}{c}\text { Atendimento em Saúde Humana; } \\
\text { Atendimento em Saúde Animal }\end{array}$ \\
\hline Empreendedorismo & Empreendedorismo \\
\hline Relações Internacionais & Relações Internacionais \\
\hline Visitas Técnicas e Gerenciais & $\begin{array}{l}\text { Visita a Empresas; } \\
\text { Visita a Estagiários }\end{array}$ \\
\hline
\end{tabular}

As áreas do conhecimento são definidas para proporcionar aos órgãos que atuam em ciência e tecnologia uma maneira ágil e funcional de agregar suas informações [3]. O sistema desenvolvido utiliza a definição realizada pela portaria no 09 da CAPES, de 23 de janeiro de 2008, para classificar as atividades de extensão quanto à área do conhecimento. A Tabela 2 mostra parte das áreas de conhecimento definida pela portaria.

Tabela 2: Áreas do Conhecimento (Parcial).

Fonte: www.capes.gov.br

\begin{tabular}{|l|c|}
\hline \multicolumn{1}{|c|}{ GRANDE ÁREA } & ÁREA DO CONHECIMENTO \\
\hline Ciências Exatas e da Terra & $\begin{array}{r}\text { Matemática; Probabilidade e Estatística; Ciência } \\
\text { da Computação; ... }\end{array}$ \\
\hline Ciências Biológicas & $\begin{array}{c}\text { Oceanografia; Biologia Geral; Genética; ... } \\
\text { Engenharias }\end{array}$ \\
\hline Ciências da Saúde & $\begin{array}{c}\text { Engenharia Civil; Engenharia Sanitária; } \\
\text { Ciências Agrárias }\end{array}$ \\
\hline Ciências Sociais Aplicadas & Medicina; Nutrição; Odontologia; ... \\
& Florestal; Engenharia Agrícola; ... \\
\hline Ciências Humanas & Direito; Administração; Turismo; ... \\
\hline Lingüística, Letras e Artes & Filosofia; Teologia; Sociologia; ... \\
\hline Multidisciplinar & Lingüística; Letras; Artes; ... \\
\hline
\end{tabular}

\section{PROJETO DO SISTEMA}

O projeto do sistema desenvolvido é apresentado nesta seção. Em geral, o projeto de um software contempla as etapas de levantamento de requisitos, modelagem, desenvolvimento e 
implantação do sistema computacional.

$\mathrm{Na}$ etapa de levantamento de requisitos, as necessidades do cliente, no caso Pró-reitoria e Coordenações de Extensão, são levantadas e balizam a modelagem e o desenvolvimento do sistema. Nesta fase são definidos os objetivos do sistema, apresentados anteriormente. Também são identificados os possíveis usuários do sistema e as operações que cada um deve realizar. Os usuários são, então, agrupados de acordo com as operações que realizam, definindo papéis ou atores [4].

A Figura 1 apresenta o diagrama de casos de uso para os usuários do sistema que atuam como administradores. Estes usuários, em geral, são responsáveis por realizar tarefas de suporte no sistema, como manutenção dos usuários e realização de cadastros básicos. No SigaProEx, os administradores são responsáveis por manter o cadastro dos campi do instituto e realizar o cadastro dos demais usuários do sistema. Cada usuário em particular é associado a um campus do IFRN de acordo com sua lotação funcional.

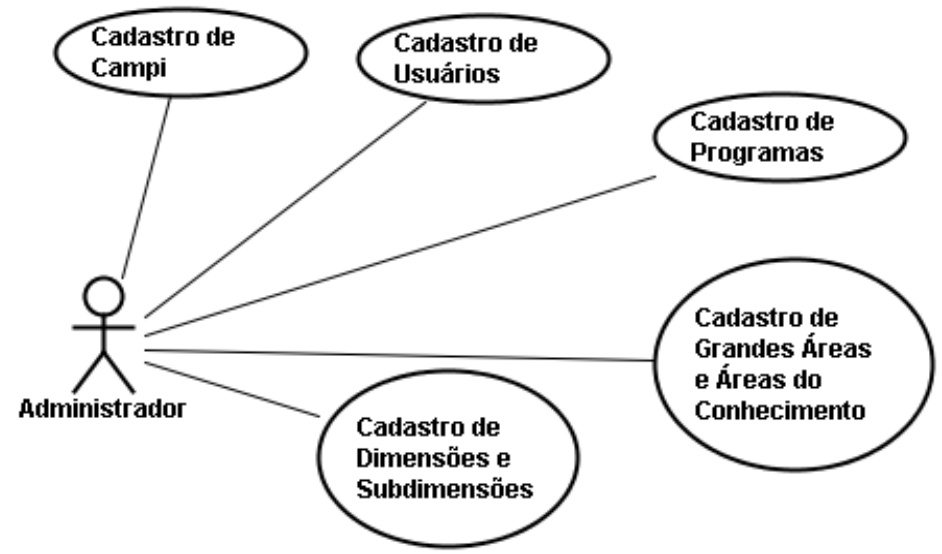

Figura 1 - Diagrama de Casos de Uso do Administrador.

Os administradores são também responsáveis por manter o cadastro das dimensões e áreas do conhecimento, descritas anteriormente, utilizadas na classificação das atividades de extensão, e dos programas de extensão desenvolvidos no instituto.

A Figura 2 apresenta o diagrama de casos de uso para pró-reitor e coordenadores de extensão. Estes usuários são responsáveis por realizar as tarefas alvo do sistema: registrar os projetos, cursos e ações de extensão; emitir certificados e gerar relatórios gerenciais para obtenção dos indicadores de desempenho. Enquanto o pró-reitor é capaz de acessar as informações em qualquer campus do instituto, coordenadores de extensão podem apenas cadastrar as informações relativas ao campus de sua lotação. 


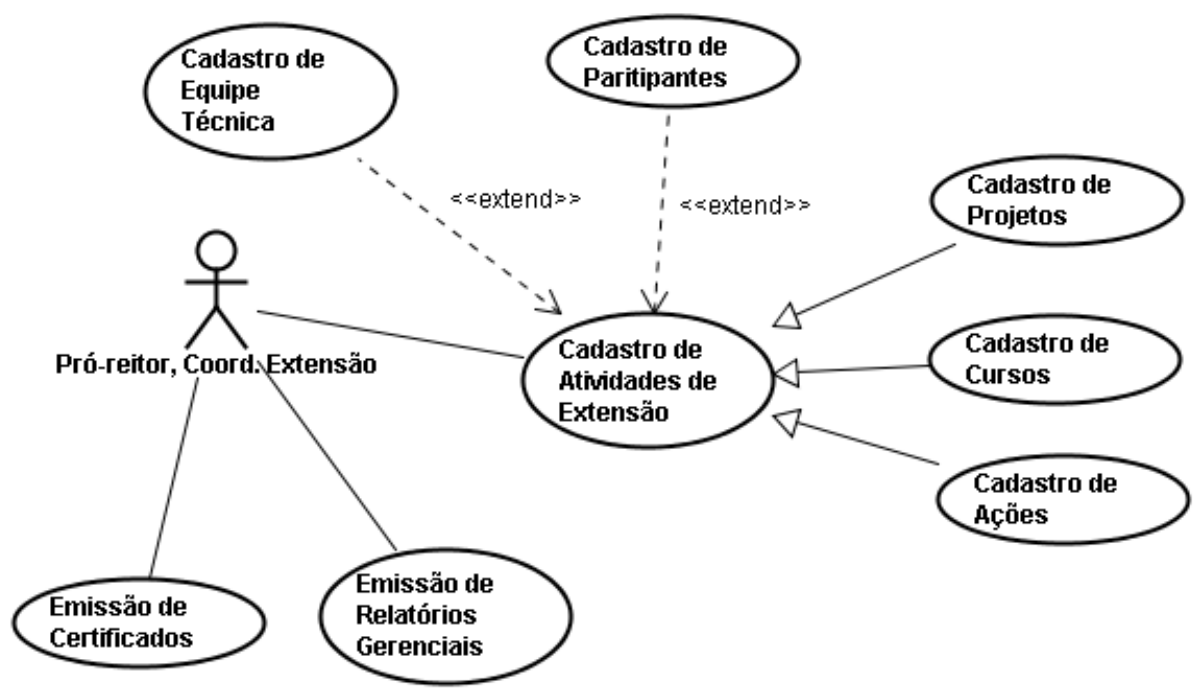

Figura 2 - Diagrama de Casos de Uso do Pró-reitor e Coordenadores de Extensão.

Uma vez definidas as funcionalidades requeridas para o sistema, o software é projetado e implementado utilizando os princípios científicos e tecnológicos da área de Análise e Desenvolvimento de Sistemas.

Para atender de forma mais adequada às necessidades requeridas para o sistema, foi desenvolvido um sistema para Internet, permitindo que as informações possam ser cadastradas e recuperadas utilizando a rede. Todas as informações são então armazenadas em um banco de dados instalado nos servidores do IFRN.

Um diagrama simplificado do banco de dados do sistema é apresentado na Figura 3. A tabela denominada Ação (acao) é responsável por armazenar as informações das atividades de extensão realizadas no instituto. Como mostra o diagrama, cada ação está associada a uma subdimensão de extensão e a uma área do conhecimento. As ações também acontecem em um campus do instituto.

Todas as pessoas envolvidas nas atividades são cadastradas na tabela de pessoas (pessoa). Cada ação possui duas relações de envolvidos: a equipe técnica que coordena e executa a ação (acao_pessoa) e os demais participantes (acao_participante).

A tabela de usuários (usuario) é utilizada para controlar o acesso dos usuários ao sistema. Conforme visto na figura, cada usuário é associado a um campus. 


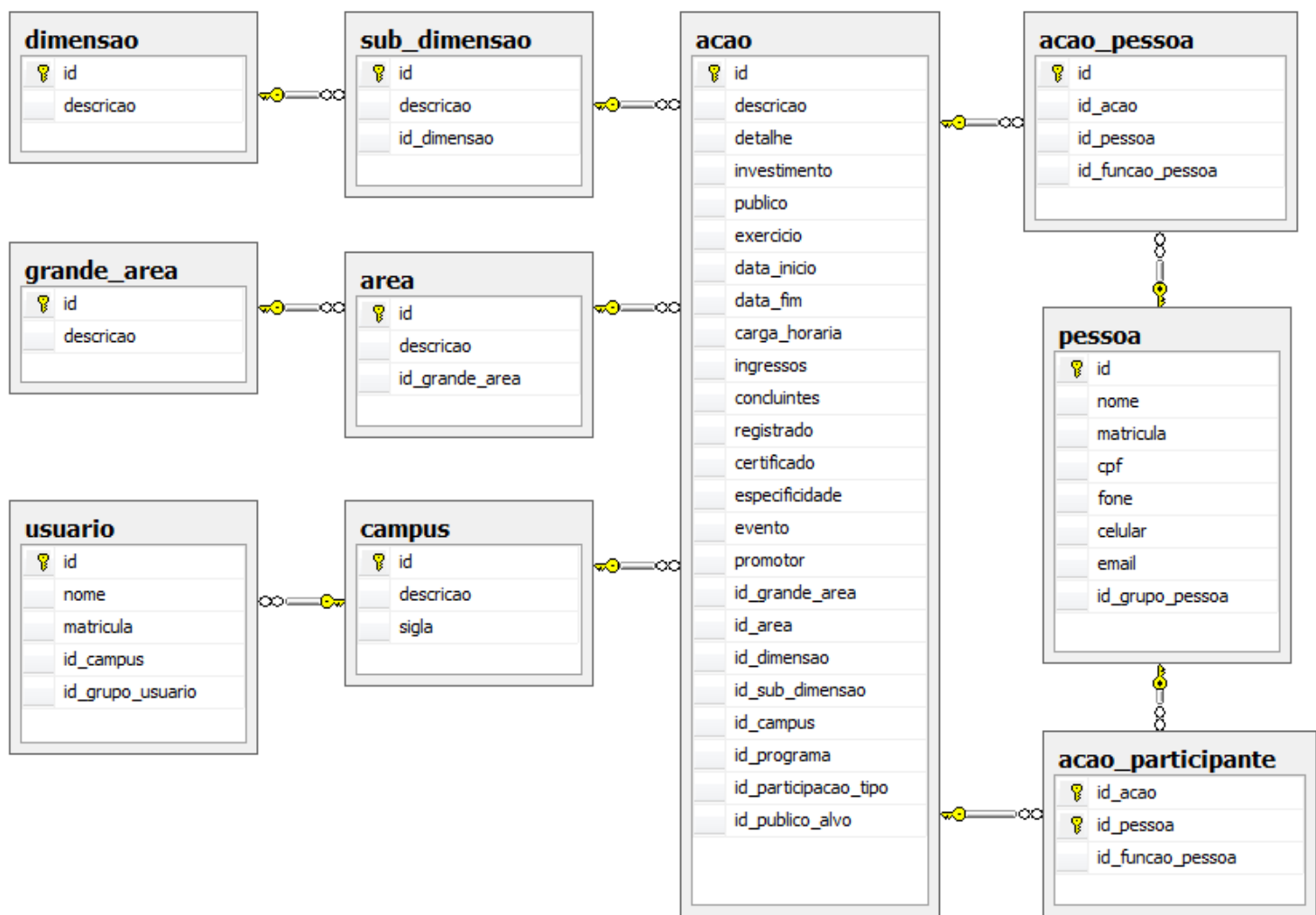

Figura 3 - Diagrama Parcial do Banco de Dados do Sistema.

\section{RESULTADOS}

O sistema SigaProEx é parcialmente apresentado nesta seção. A Figura 4 apresenta a página de índice para os usuários administradores, que possuem acesso a todos os cadastros do sistema.

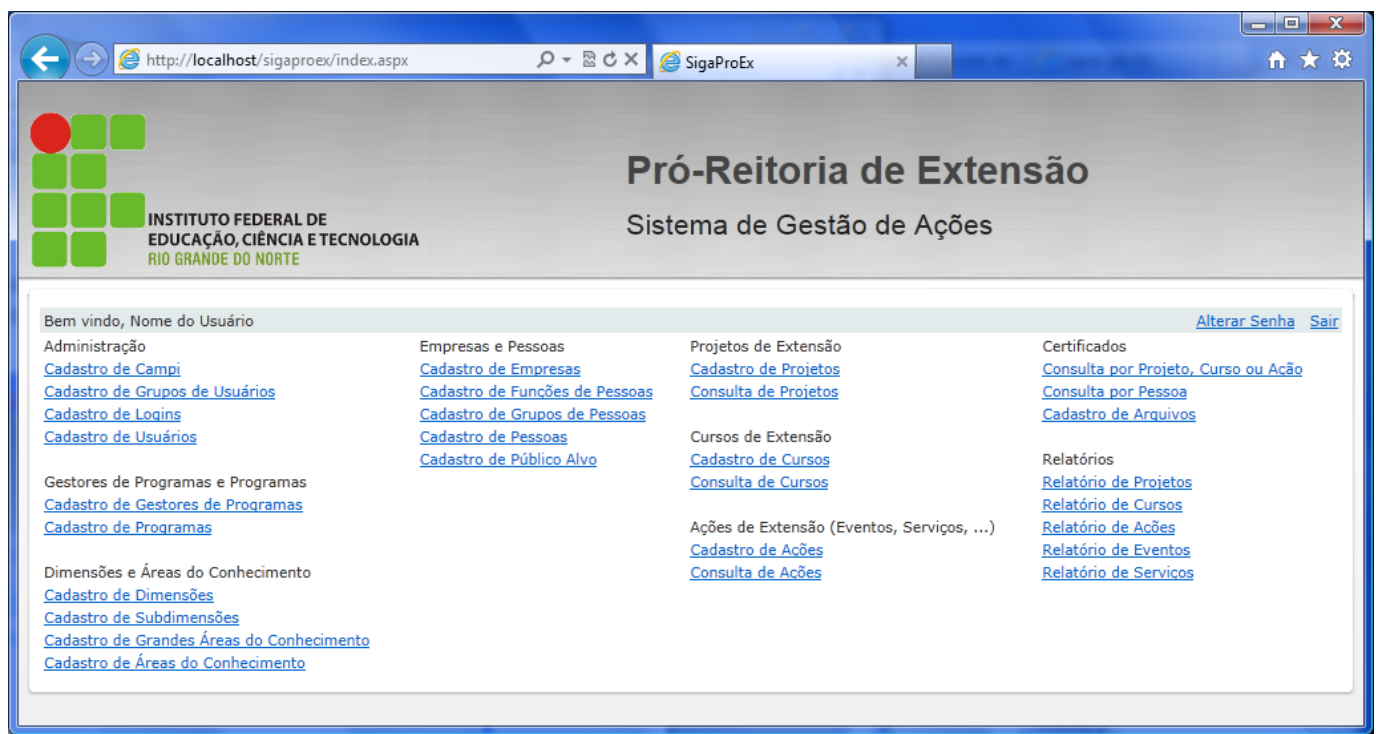

Figura 4 - Página de Índices do Sistema de Gestão de Ações.

As Figuras 5 e 6 mostram o registro de um projeto de extensão no campus Natal-Central. No 
momento do cadastro, a atividade também é associada a uma área do conhecimento e uma subdimensão de extensão. As atividades também podem ser associadas a um programa de extensão, conforme visto na Figura 6.

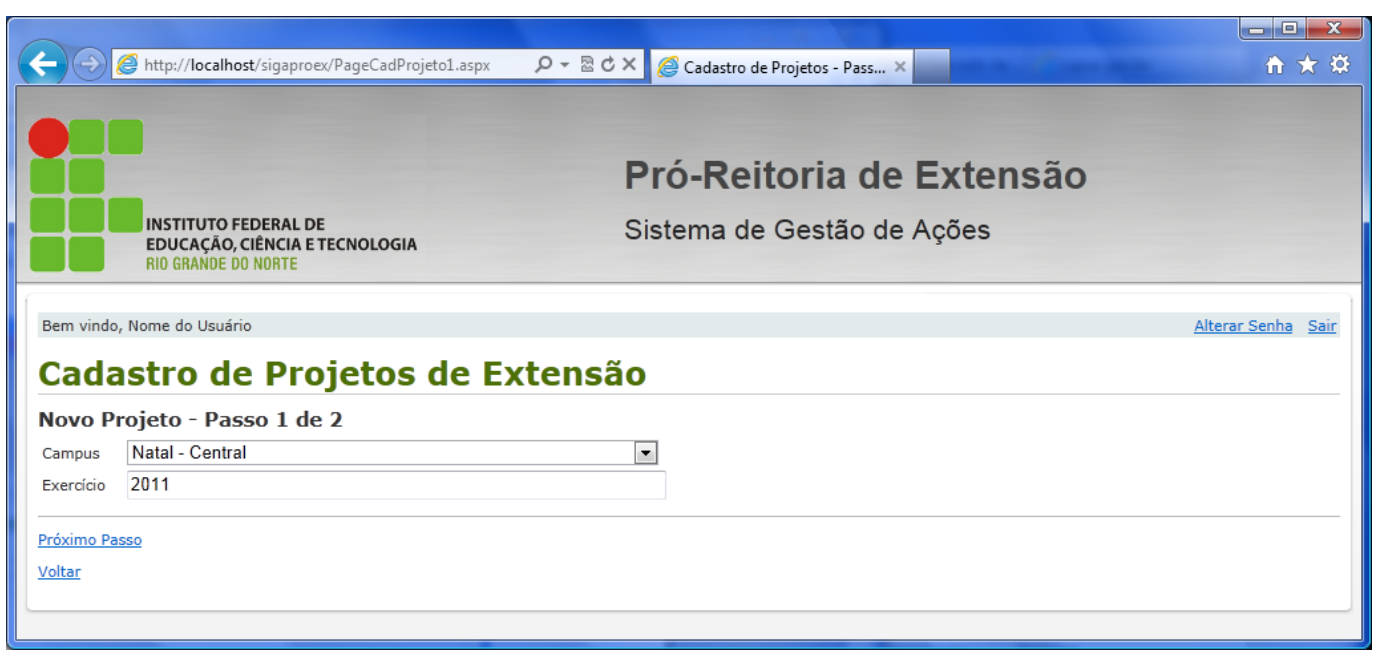

Figura 5 - Página de Cadastro de Projetos de Extensão - Passo 1/2.

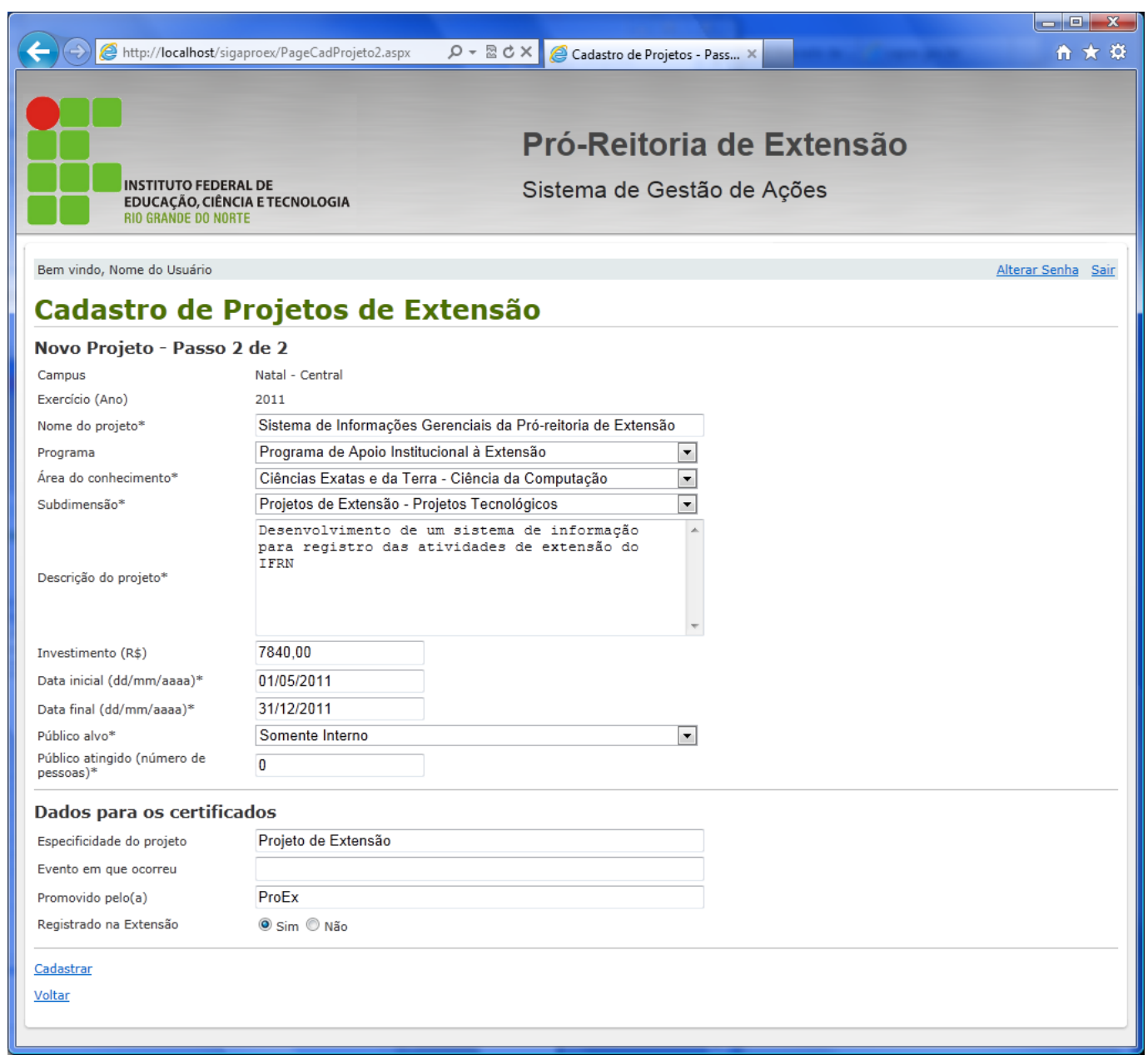

Figura 6 - Página de Cadastro de Projetos de Extensão - Passo 2/2. 
A Figura 7 mostra o cadastro da equipe técnica envolvida na execução de um projeto. Cada membro é associado a um grupo utilizado para obtenção dos indicadores utilizados pela extensão. Os membros também possuem funções específicas nas atividades, utilizadas na impressão dos certificados. É possível ainda registrar a data de entrega dos certificados.

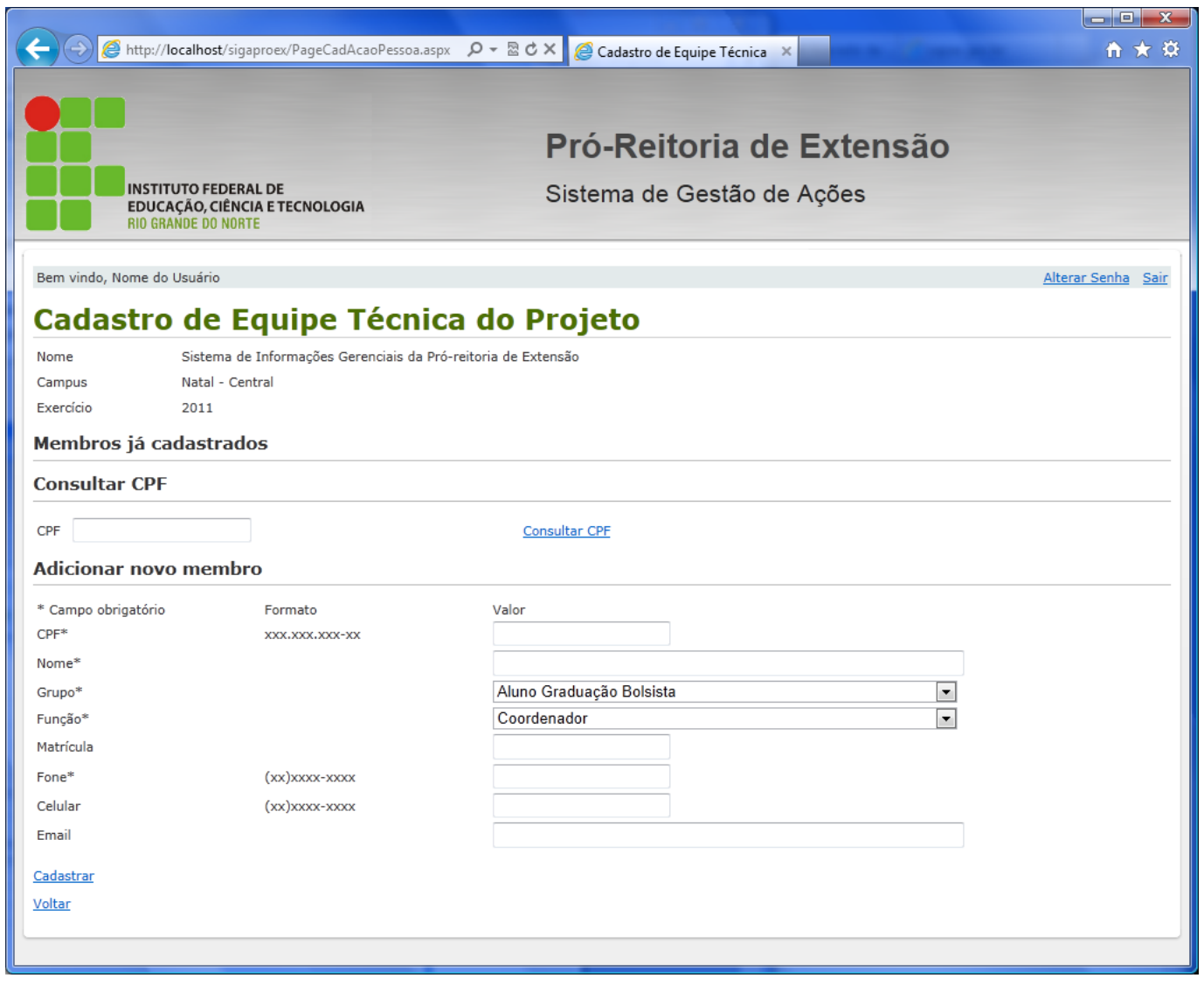

Figura 7 - Página de Cadastro de Equipe Técnica do Projeto.

A página de consulta de certificados é apresentada na Figura 8. O sistema possibilita a busca do pessoal envolvido nas atividades de extensão pelo nome, CPF ou atividade desenvolvida. A impressão dos certificados é realizada utilizando um recurso de mala direta para dar maior flexibilidade na confecção do lay-out de impressão. 


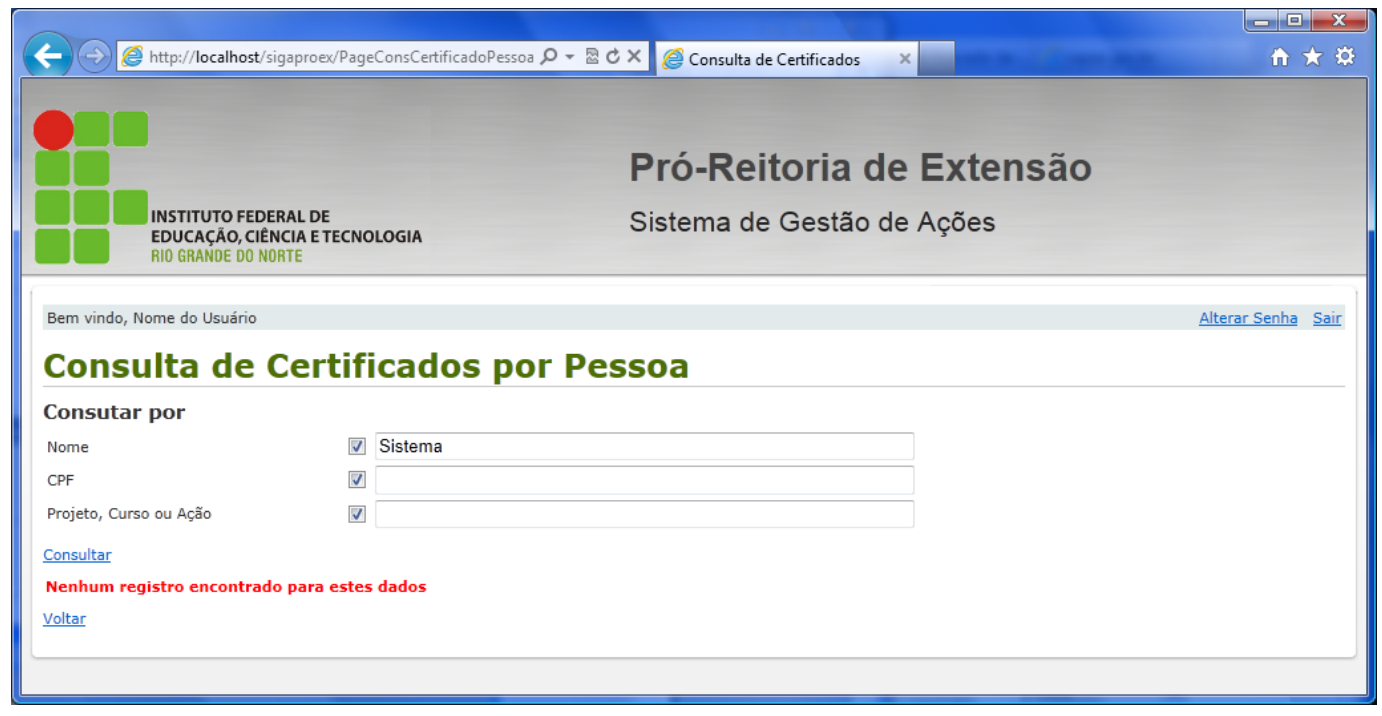

Figura 8 - Página de Consulta de Certificados.

Finamente, um relatório gerencial com indicadores sobre projetos de extensão é apresentado na Figura 9.

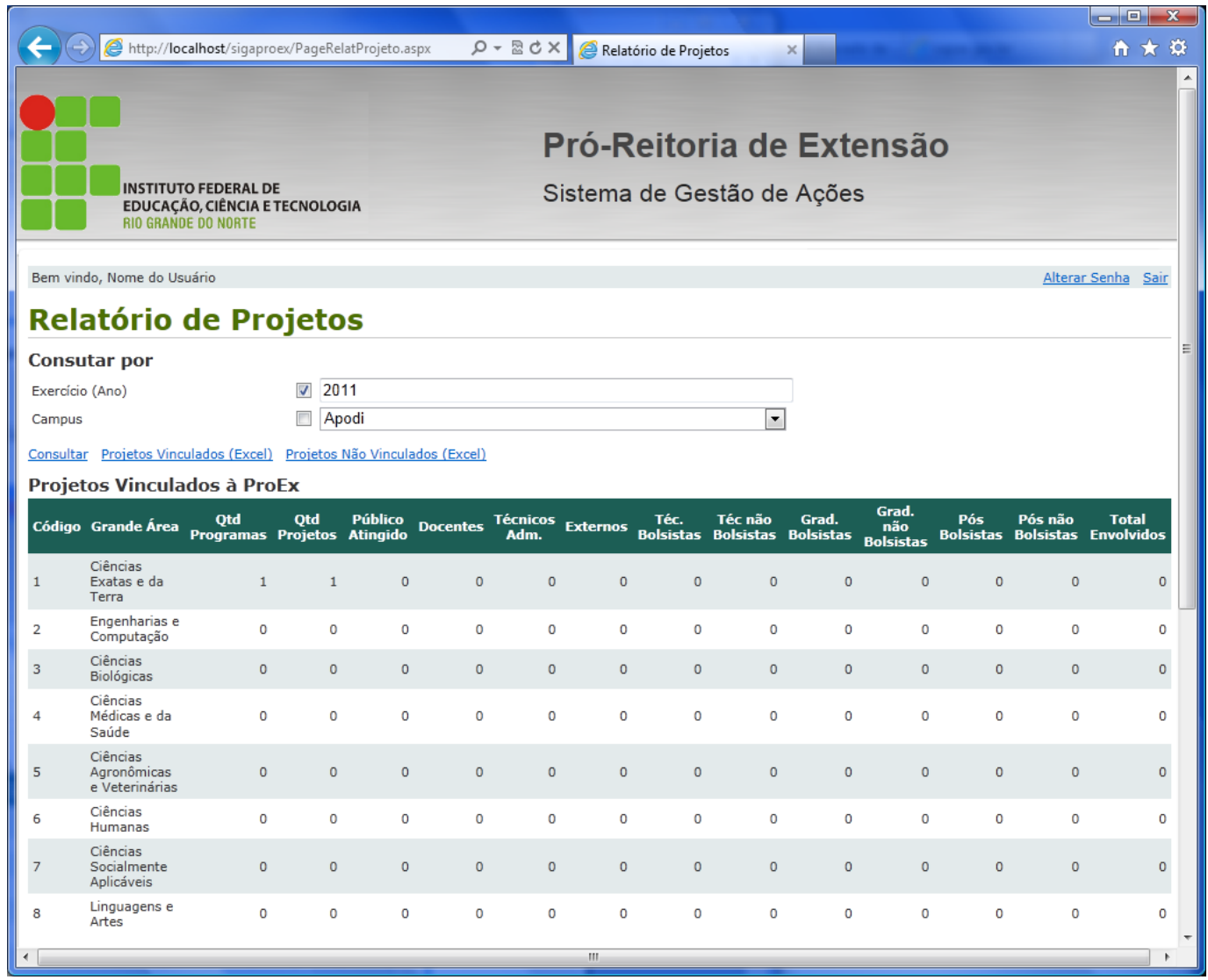

Figura 9 - Página de Relatório de Projetos. 


\section{CONCLUSÕES}

O presente artigo apresentou um sistema de informação desenvolvido para registrar as atividades de extensão do Instituto Federal do Rio Grande do Norte.

Espera-se que o sistema venha facilitar a realização de tarefas operacionais realizadas rotineiramente pelas coordenações de extensão, como registrar as atividades e emitir certificados, além de auxiliar a obtenção dos indicadores necessários à Pró-reitoria de Extensão.

Atualmente, todo o gerenciamento de informações das coordenações de extensão é realizado com o auxílio de planilhas eletrônicas. Desta forma, o sistema desenvolvido pode e deve servir como um protótipo para o desenvolvimento de um sistema que atenda, cada vez melhor, às coordenações e Pró-reitoria de Extensão do IFRN.

\section{REFERÊNCIAS BIBLIOGRÁFICAS}

1. Plano de Desenvolvimento Institucional 2009-2014. Disponível em http://portal.ifrn.edu.br/institucional/planejamento

2. Concepção da Extensão. Fórum dos Diretores de Extensão dos Centros Federais de Educação Tecnológica.

3. Tabela de Áreas de Conhecimento. Disponível em http://www.capes.gov.br/avaliacao/tabela-deareas-de-conhecimento

4. GUEDES, G.T.A. UML - Uma Abordagem Prática. Novatec Editora LTDA, 2004. 